\title{
The comparison between the effects of nano and conventional crease recovery treatment process parameters
}

\begin{abstract}
In this study, chemicals with different particle size are applied via padding application to $100 \%$ woven cotton fabric samples to make them crease resistant. After padding, drying and curing operations, some mechanical tests; abrasion resistance, crease recovery angle, tensile strength, tear strength and whiteness index difference by spectrophotometer are handled.By evaluating results of these mentioned tests, multi-axial graphics are drawn by MATLAB and the areas are calculated. These calculated areas lead us to find the best recipe. According to the results,small sized crosslinking agent gives better values than conventional crosslinking agent.
\end{abstract}

Volume 4 Issue 4 - 2018

\author{
Bilgen Kapar, Cem Gunesoglu \\ Department of Textile Engineering, Gaziantep University, Turkey
}

Correspondence: Kapar B, Department of Textile Engineering, Gaziantep University, Gaziantep, Turkey, Tel +90342 31727 17, Fax+90342 31727 06, Email celikturk@gantep.edu.tr

Received: April 29, 2018 | Published: July 02, 2018

Keywords: crease resistance, DMDHEU, particle size, cotton fabric, crease recovery angle

\section{Introduction}

Finishing of textiles enables to give to the textile material high quality, visual appearance, best touch and the most significant to improve desirable properties. ${ }^{1}$ Textile market has dealed with easy care processes, crease resistant textiles over the years. Creases have a negative effect on fabric surface especially for cellulose fabrics., ${ }^{2,3}$ When fabric is not treated with any crease recovery finish, this fabric has low recovery because there are hydrogen bonds in cellulose. When a load is applied to the cellulose textiles the hydrogen bonds are slipped to each other and these bonds are broken. When the load is removed the bonds make other bonds so crease occurs. ${ }^{2,4}$ There are some contributing causes affect creases. These contributing causes are; fiber type, bending performance of fiber, fiber diameter, high orientation region of fibers, molecular structure of fiber, fiber cross section type, yarn twist, weft-warp density, fabric construction. ${ }^{5}$ Crease resistant finish is used commonly in textile industry to give anti-crease property to cotton fabrics and garments. Because untreated cellulose has poor recovery, so it is necessary to apply crease resistant finish. ${ }^{6,7}$ The creasing behavior of cotton is observed because of free hydroxyl groups in amorphous region. Cross-linking of polymer chains prevent creasing of cellulose fabrics, cross-linking prevents water to enter in the chains. ${ }^{6,8}$ So, cellulose cross-linking is very crucial for textile chemical process and the basic application in huge textile finishing industry.In general crease recovery finishes are applied by $\mathrm{N}$-methylol compounds and urea chemicals. But it is known that these reagents include formaldehyde known as human carcinogen. So resin finishing producers has made researches to find a non-formaldehyde resin finishing treatment to obtain healthy resins for practical use. DMDHEU (dimethyl dihydroxy ethylene urea) is generally used as a low-formaldehyde cross-linking agent. ${ }^{9,10}$ The main purpose of study is to evaluate the differences between results of testsdone with small particle size cross-linking agent and conventional particle size cross-linking agent. With developing textile chemical technology, textile chemicals are produced small sizes in order to achieve strong penetrationto the textile surface and better physical properties.For this study $100 \%$ woven cotton fabric is acquired and recipes (both conventional DMDHEU and nano marked Nanolink) are applied to the fabric samples. After physical tests multiaxial graphics are drawn and the area between the axis are calculated by MATLAB. There are some studies related with different size comparisons. But in this study, the parameter's intersection areas are calculated. The bigger area is detected and the best recipe is chosen.

\section{Experimental}

\section{Materials}

$100 \%$ cotton woven fabric $\left(55 \times 40\right.$ warps $\mathrm{x}$ weft, $\left.200 \mathrm{~g} / \mathrm{m}^{2}\right)$ is employed in the study; the fabric is scoured and bleached by the supplier (Kardesler Boya, Gaziantep, Turkey). Conventional and nano marked crosslinking agent, macrosilicone softener are supplied by Rudolf Duraner, and magnesium chloride as catalyst is supplied by MERCK (Table 1).

The crease recovery treatment is applied both two reagents. Recipes include crosslinking agent, silicone softener and magnesium chloride as catalyst. Recipe with conventional crosslinking agent is coded as $\mathrm{C} 1$, recipe with nano marked crosslinking agent is coded as C2 (Table 2).

Multimodal size distribution analyses of DMDHEU reagents are done to calculate the particle size of these reagents.

FTIR analyses of DMDHEU reagents are done to see the characteristics of these reagents.

\section{Methods}

After finishing application the physical tests are done to the fabric samples which are treated with crease resistant finish. All tests are done at laboratory conditions with temperature $21+1^{\circ} \mathrm{C}$ and relative humidity $65+2 \%$ RH Textile Engineering Department, Gaziantep University.

Tensile strength: Tensile strength measurements of samples aredone by James H. Heal Titan Universal Strength Tester 2. TS EN ISO 13934-1 'Tensile properties of fabrics-Part I: Determination of maximum force and elongation at maximum force using the strip method $(200 \mathrm{~mm}-100 \mathrm{~mm})$ ' is used to determine the tensile strength and elongation of fabric. 
Table I Test materials and chemicals for crease recovery treatment for $100 \%$ cotton fabric used in study

\begin{tabular}{lll}
\hline Materials & Description & Manufacturer \\
\hline Cotton fabric & I00\% cotton woven fabric $\left(45 \times 23\right.$ warps $x$ weft, $200 \mathrm{~g} / \mathrm{m}^{2}$ & Kardesler boya Gaziantep, Turkey \\
Conventional crosslinking agent & Rucon fan N-methylol dihydroxy ethylene & Rudolf Duraner \\
Nano marked crosslinking agent & Ruco nanolink com 48I3 & Rudolf Duraner \\
Macro silicone & For pad process pH values 5-6. It is resistant to yellowing & Rudolf Duraner \\
Magnesium chloride & Magnesium chloride hexahydrate. $99 \% \mathrm{MgCl} 2$ & MERCK I.05833.I000
\end{tabular}

Table 2 Crease recovery treatment recipes for $100 \%$ cotton fabric

\begin{tabular}{llllll}
\hline Recipes & Cross linking agent $(\mathbf{g} / \mathbf{L})$ & Softener $(\mathbf{g} / \mathbf{L})$ & $\begin{array}{l}\text { Catalyst } \\
(\mathbf{g} / \mathbf{L})\end{array}$ & pH & Drying-Curing process \\
\hline $\mathrm{Cl}$ & 40 & 20 & 10 & 5 & $130^{\circ} \mathrm{C} 4$ minute $170^{\circ} \mathrm{C} 70$ seconds \\
$\mathrm{C} 2$ & 40 & 20 & 10 & 5 & $130^{\circ} \mathrm{C} 4$ minute $170^{\circ} \mathrm{C} 70$ seconds \\
\hline
\end{tabular}

Tearing strength: Tearing strength is also measured by James H. Heal Titan Universal Strength Tester 2. TS EN 13937-2 'Tear properties of fabrics- Part II: Determination of tear force of trouser -shaped test specimens' is used to determine the tear strength.

Crease recovery angle: Crease recovery angles are measured according to AATCC Test Method 66 'Wrinkle Recovery of Woven Fabrics: Recovery Angle-1998' by James H. Heal \& Co. Ltd. Crease Recovery Angle tester.

Abrasion resistance: Abrasion resistance values are measured by Martindale Abrasion Tester. TS EN ISO 12947-3 'Determination of the abrasion resistance of fabrics by the Martindale method- Part 3: Determination of mass loss' standard is used.

Whiteness index: Whiteness (WI) index is measured by Hunterlab Color Quest II Spectrophotometer Device. The device is adjusted D $65 / 10^{\circ}$.

\section{Results and discussions}

Figure 1 shows the multimodal size distribution analyses of the DMDHEU reagents that are used to calculate the effective diameter (Deff). Deff is the diameter that a sphere would have to diffuse at the same rate as the particle being measured and may result from one or more populations of the particles present in the emulsions. If the system is polydisperse, Deff is an average diameter, and if weighted by intensity, it is an averaged intensity of scattered light by each particle. From the multimodal size distribution, it appeared that in the investigated DMDHEU reagents nano-marked and conventional crosslinking agents ( $\mathrm{C} 1$ and $\mathrm{C} 2$ respectively), there is one remarkable population of particles arising major fluctuation; and the fluctuation of $\mathrm{C} 1$ corresponded to larger diameters than that of $\mathrm{C} 2$; thus Deff is measured to be $739,6 \mathrm{~nm}$ for $\mathrm{C} 2$ and $851,8 \mathrm{~nm}$ for $\mathrm{C} 1$ (Figure 1). The polydispersity values for $\mathrm{C} 2$ and $\mathrm{C} 1$ were 0,315 and 0,319 respectively, which means that emulsions prepared had similar distributions.

FTIR analyses of the DMDHEU reagents are shown in Figure 2. The IR spectra for both DMDHEU reagents shows also the characteristic peaks of $\mathrm{O}-\mathrm{H}$ stretching (around $3300 \mathrm{~cm}^{-1}$ ), $\mathrm{C}=\mathrm{O}$ stretching (around $1700 \mathrm{~cm}^{-1}$ ) and $\mathrm{C}-\mathrm{N}$ stretching (around 1380 $\mathrm{cm}^{-1}$ ), C-H bending (around $1236 \mathrm{~cm}^{-1}$ ) and C-O stretching (around
$1020 \mathrm{~cm}^{-1}$ ) (Figure 2). The chemical compositions of the reagents are concluded as similar; however the peak strengths were different for $\mathrm{O}-\mathrm{H}$ and $\mathrm{C}-\mathrm{O}$ adsorptions representing the difference in the number of glyoxals within reagent structure.

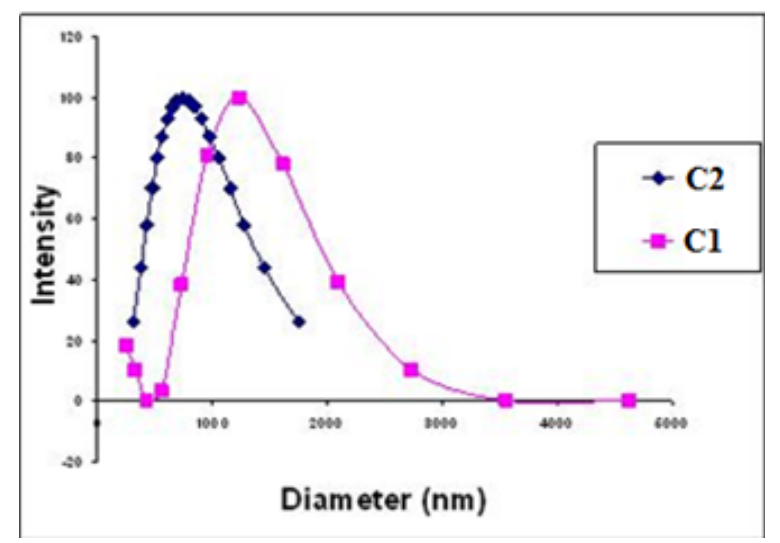

Figure I Multimodal size distributions of DMDHEU reagents.

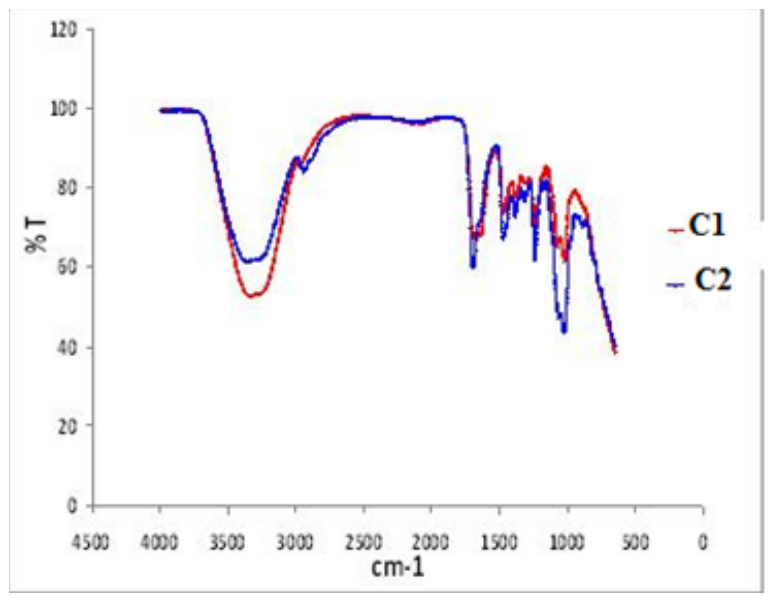

Figure 2 FTIR spectrums of DMDHEU reagents 
Application of crease resistant finish is performed using a laboratory type padding machine manufactured by Prowhite Testing Equipments with a model no: PDF01-A/0601001 with 220 VAc $50 / 60 \mathrm{~Hz}$. After padding operation, the fabric samples are dried and cured with laboratory type dyeing-curing machine manufactured by Prowhite Testing Equipments. After doing application, the physical tests are done and then the multiaxial graphs are drawn by MATLAB. The importance of these multiaxial graphics is to indicate the biggest area. As per our assumption ,the biggest area will give the best recipe for us, because the axis of the graphics are; fabric tensile warp, fabric tensile weft, tear strength warp, tear strength weft, crease recovery angle warp, crease recovery angle, whiteness index and abrasion resistance. For each axis, the biggest values give desired values, so it means biggest values give biggest areas.

Tensile strength: When warp direction tensile strength is examined, the difference of $\mathrm{C} 1$ and $\mathrm{C} 2$ result is pretty close to each other, extension also almost same for both of recipes. Crease recovery finish application due to crosslinking agent decreases the tensile strength ${ }^{11}$ results when comparing with untreated fabric samples. Tensile strength results in warp direction are decreased nearly $51 \%$ for $\mathrm{C} 1$ recipe, $53 \%$ for $\mathrm{C} 2$ recipe. When the weft direction is examined, $55 \%$ decrease for $\mathrm{C} 1,42 \%$ decrease for $\mathrm{C} 2$ recipe (Table 3 ). Bilgen ${ }^{12}$ made a crease recovery study with DMDHEU, and he found the decrease about $50 \%$ in tensile strength (Figure 3 ).

Table 3 Tensile strength $(\mathrm{N})$ and extension (\%) results for untreated sample, $\mathrm{Cl}$ and $\mathrm{C} 2$ recipes.

\begin{tabular}{lll}
\hline Samples & Mean force $(\mathbf{N})$ & Mean extention (\%) \\
\hline Untreated warp & 834,57 & 23,51 \\
Cl warp & 406,89 & 17,5 \\
C2 warp & 393,91 & 17,31 \\
Untreated weft & 356,79 & 10,81 \\
C1 weft & 159,69 & 7,05 \\
C2 weft & 206,82 & 7,79 \\
\hline
\end{tabular}

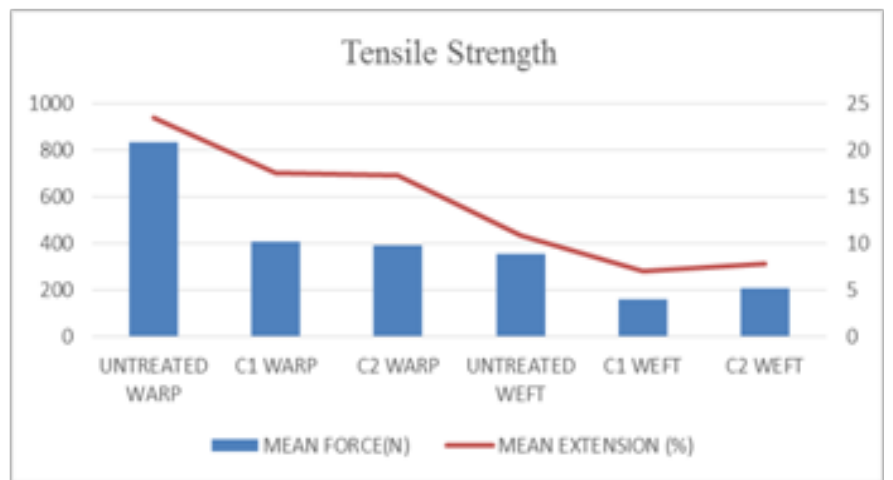

Figure 3 Tensile strength $(\mathrm{N})$ and extension (\%) graphics for untreated sample, $\mathrm{Cl}$ and $\mathrm{C} 2$ recipes.

Tearing strength: When the results are compared, the tearing strength results are decreased nearly $74 \%$ for both recipes when comparing untreated samples like the study was done. ${ }^{13}$ In weft direction the tearing strength loss is about $30 \%$ for $\mathrm{C} 1$ recipe and $38 \%$ for $\mathrm{C} 2$ recipe (Figure 4). It is clearly said that the loss is more in $\mathrm{C} 2$ recipe than $\mathrm{C} 1$ recipe. It is known that in weft direction less strong yarns are used than warp yarns.

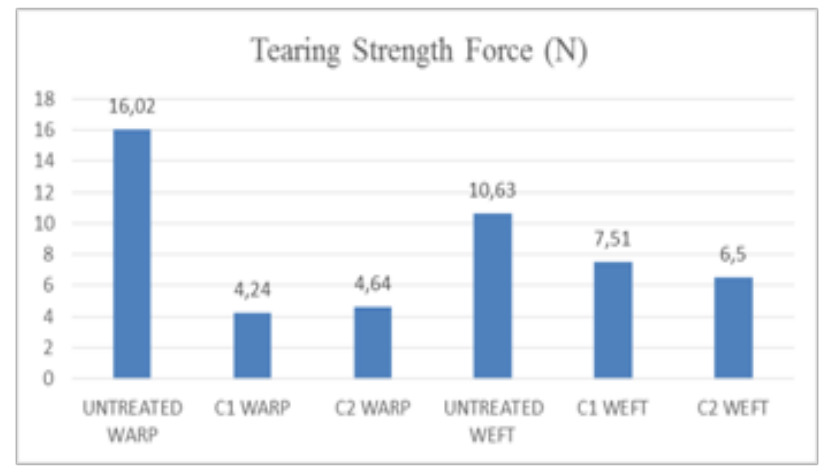

Figure 4 Tearing strength $(\mathrm{N})$ graphics for untreated sample, $\mathrm{Cl}$ and $\mathrm{C} 2$ recipes.

Crease recovery angle: When crease recovery angle results are examined (Table 4), the crosslinking agent increased the crease recovery angles. ${ }^{6}{ }^{12}$ It is achieved to obtain bigger crease recovery angle value with $\mathrm{C} 1$ recipe. As expected, crease recovery angle increases when tensile strength decreases. ${ }^{11}$

Abrasion resistance: When abrasion resistance results are examined (Table 5), the results show similar to tensile strength. Because tensile strength and abrasion resistance have similar tendency. ${ }^{14}$

Whiteness index: When the results are examined, whiteness index of untreated fabric is 61.73 , treated with $\mathrm{C} 1$ is 55.84 , approximately decreased about $10 \%$ and treated with $\mathrm{C} 2$ is 54.02 , approximately decreased about $12 \%$. DMDHEU application causes difference on whiteness index (Table 6). ${ }^{15}$

Table 4 Crease recovery angle results

\begin{tabular}{ll}
\hline Samples & Total crease recovery angle $\left(^{\circ}\right)$ \\
\hline Untreated & 231,25 \\
$\mathrm{Cl}$ & 280,25 \\
$\mathrm{C} 2$ & 277,5 \\
\hline
\end{tabular}

Table 5 Abrasion resistance results

\begin{tabular}{lll}
\hline Samples & Weight loss (\%) & Thickness loss (\%) \\
\hline Untreated & 1,34 & 3,17 \\
$\mathrm{Cl}$ & 8,85 & 14,75 \\
$\mathrm{C} 2$ & 18,11 & 25,25 \\
\hline
\end{tabular}

Table 6 Whiteness index results

\begin{tabular}{ll}
\hline Samples & CIE whiteness index \\
\hline Untreated & 61,73 \\
C1 & 55,84 \\
C2 & 54,02
\end{tabular}




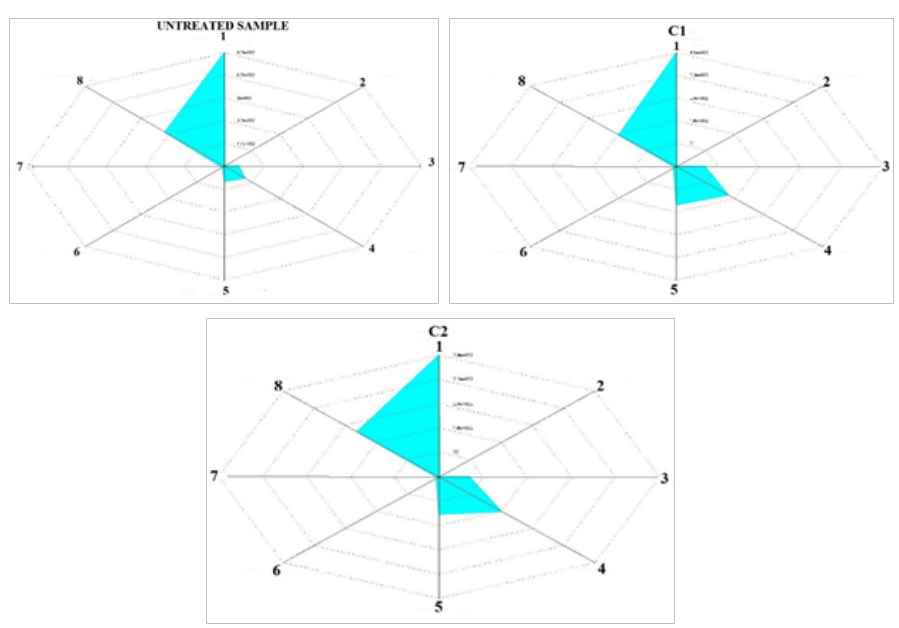

Figure 5 Matlab Area Calculation of samples. A) Untreated Fabric Sample (Total Area 10604I, 29 unit), B) CI Recipe (Total Area 3I I56, 94 units), C) C2 Recipe (Total Area 36037, I unit). In Figure 5, the numbered axis is following results;

a. Fabric Tensile (warp direction)

b. Abrasion Resistance

c. Whiteness index

d. Crease Recovery Angle (weft direction)

e. Crease Recovery Angle (warp direction)

f. Tear Strength (weft direction)

g. Tear Strength (warp direction)

h. Fabric Tensile (weft direction)

Multiaxial graphics are drawn by MATLAB, and the biggest area is chosen to determine the best recipe for this study. According to results obtained from multiaxial graphics, the biggest area gives the best recipe. Because the assumption for this study is "The higher the tensile strength (in warp and weft directions), the tear strength (in warp and weft directions), the crease recovery angle (in warp and weft directions), the whiteness index and the abrasion resistance retention (as the ratio of abraded mass to total fabric mass), the greater the area and the more acceptable the recipe is". The crease recovery angle becomes significant with the least physical property decrease.So it could not be true when we decide the recipe just only according to crease recovery angle result (Figure 5). According to the multiaxial graph results $\mathrm{C} 1$ recipe has the biggest area. Also the total crease recovery angle of $\mathrm{C} 1$ recipe is $280,35^{\circ}$, it is the biggest angle among three situation, untreated fabric sample $\left(231,25^{\circ}\right), \mathrm{C} 1$ recipeand $\mathrm{C} 2$ recipe $\left(277,5^{\circ}\right)$.

\section{Conclusion}

When the crease recovery angle increases, the fabric has less tendency to crease. ${ }^{16}$

The results shows that for cotton samples used in the study, the most optimum crease recovery treatment formula has been obtained as following $\mathrm{C} 1$ recipe:

a. Crease recovery agent with bigger particle size (conventional) with $1: 4$ catalyst ratio b. Softener with 1:2 agent ratio

c. Curing at $130^{\circ} \mathrm{C}$

d. Softener with 1:2 agent ratio

e. Curing at $130^{\circ} \mathrm{C}$

\section{Acknowledgements}

None.

\section{Conflict of interest}

Author declares there is no conflict of interest in publishing the article.

\section{References}

1. Can Y, Akaydin M, Turhan Y, et al. Effect of wrinkle resistance finish on cotton fabric properties. Indian J Fiber \& Textile Res. 2009;34183-6.

2. Hauser PJ, Smith CB, Hashem MM. Ionic cross linking of cotton. Autex Research J. 2004;4(2):95-100.

3. Mortazavi SM, Boukany PE. Application of mixtures of Resin Finishing to achieve some physical properties on interlining cotton fabrics: I-effect of stiffening and cross linkingagents. Iranian Polymer J. 2004;13:21318.

4. Sahin UK, Gursoy NC, Hauser P, et al. Optimization of ionic cross linking process: an alternative to conventional durable press finishing. Textile Research J. 2009;79(8):744-52.

5. Bellini P, Bonetti F, Franzetti E, et al. Finishing Reference Books of Textile Technologies. Acimit Fundation; 2001.

6. Hashem M, Hauser P, Smith B, et al. Wrinkle recovery for cellulosic fabric by means of ionic cross linking. Textile Research J. 2003;73(9):762-66.

7. Schramm C, Rinderer B, Binder WH, et al. Treatment of 1, 3-dimethylol-4, 5-dihydroxyimidazolidine-2-one finished cellulosic material with tetraethoxysilane or glycidyloxypropyl-trimethoxysilane solutions. $J$ Materials Science. 2005;40(8):1883-91.

8. Ramachandran T, Gobi N, Rajendran V, et al. Optimization of process parameters for crease resistant finishing of cotton fabric using citric acid. Indian J Fibre \& Textile Research. 2009;34:359-367.

9. National Textile Center. Abrasion Resistance of Durable Press Finished Cotton. Pennysylvania; 2001.

10. www.esefgazi.edu.tr/html/yayinlar/4_pdf/4_11.pdf

11. Shet RT, Yabani AM. Crease-recovery and tensile-strength properties of unmodified and modified cotton cellulose treated with crosslinking agents. Textile Research J. 1981;51(11):740-44.

12. Bilgen M. Wrinkle Recovery for Cellulosic Fabric By Means of Ionic Crosslinking. North Carolina: North Carolina State University; 2005.

13. Choi HM. Nonformaldehyde polymerization-crosslinking treatment of cotton fabrics for improved strength retention. Textile Research J. 1992;62(10):614-18.

14. Rowland SP, Bertoniere NR, Martin LF. The Development of Abrasion Resistance and Breaking Strength in Durable-Press Cotton Fabrics. Textile Research J. 1974;44(8):595-99.

15. Dehabadi VA, Buschmann HJ, Gutmann JS. Durable press finishing of cotton fabrics: an overview. Textile Research J. 2013;83(18):1974-95.

16. Kapar BC, Gunesoglu C. Crease Recovery Treatment via Pad and Chemical Foam System with Different $\mathrm{pH}$ Values. J Textiles \& Engineer. 2013;20(90):25-31. 